\title{
Determination of Nitrofuran Metabolites in Complex Food Matrices Using a Rough, Cheap, Easy-Made Wooden-Tip-Based Solid-Phase Microextraction Probe and LC-MS/MS
}

\author{
Xiaoming Gong $\mathbb{D},{ }^{1}$ Kai Li $\mathbb{D},{ }^{1}$ Wenjuan Xu $\mathbb{D},{ }^{1}$ Liming Jin $\mathbb{D}^{2},{ }^{2}$ Mengxiao Liu $\left(\mathbb{D},{ }^{1}\right.$ \\ Mengmeng Hua $\mathbb{D}^{1},{ }^{1}$ and Guoning Tian $\mathbb{D}^{1}$ \\ ${ }^{1}$ Comprehensive Technical Service Center of Weifang Customs, Weifang 261041, China \\ ${ }^{2}$ Key Laboratory of Biotechnology and Bioresources Utilization, Ministry of Education, Dalian Nationalities University, \\ Dalian 116605, China \\ Correspondence should be addressed to Kai Li; likai1022@icloud.com
}

Received 23 September 2021; Accepted 2 February 2022; Published 1 March 2022

Academic Editor: Serkan Selli

Copyright (c) 2022 Xiaoming Gong et al. This is an open access article distributed under the Creative Commons Attribution License, which permits unrestricted use, distribution, and reproduction in any medium, provided the original work is properly cited.

\begin{abstract}
In this study, a rough, cheap, easy-made wooden-tip-based solid-phase microextraction (SPME) probe was first developed for simultaneous determination of 4 nitrofuran metabolite derivatives in complex food matrices via LC-MS/MS. A simple dip-coating method was used to coat wooden tips with biocompatible polyacrylonitrile (PAN) and N-vinylpyrrolidone-co-divinylbenzene, also known as HLB particles, which served as the extractive substrate in the proposed device. Compared with the traditional solidphase extraction (SPE) method, the proposed device shortens sample clean-up time, reduces solvent consumption, and decreases testing costs. In addition, the main parameters affecting the SPME procedure efficiency were investigated in detail and the optimal conditions were found. The method was validated using three different food matrixes (pork, croaker, and honey) by spiking with the four metabolites at $0.5,1.0$, and $5.0 \mu \mathrm{g} / \mathrm{kg}$, as well as their internal standards. The average recovery of all nitrofuran metabolite derivatives ranges from 97.4-109.5\% (pork), 87.5-112.7\% (croaker), and 98.6-109.0\% (honey). Relative standard deviations were all $<10 \%$ for intraday and interday precision. The values of limit of detection and limit of quantification were, respectively, ranging from 0.011 to 0.123 and 0.033 to $0.369 \mu \mathrm{g} / \mathrm{kg}$ (pork), 0.009 to 0.112 and 0.027 to $0.339 \mu \mathrm{g} / \mathrm{kg}$ (croaker), and 0.010 to 0.131 and 0.030 to $0.293 \mu \mathrm{g} / \mathrm{kg}$ (honey). The presented method was applied to the analysis of real positive samples.
\end{abstract}

\section{Introduction}

Nitrofurans (NFs) are a group of synthetic broad-spectrum antibacterial drugs with a 5-nitrofuran ring skeleton structure [1]. They have been widely used as feed additives in poultry, livestock, honey bee, and aquaculture to promote growth or as antimicrobial agents to control diseases caused by Salmonella and E. coli infections [2]. The nitro group, located in the 5-C position of the furan ring, contributes most to bactericidal activity. The metabolic activation of NFs is achieved through enzymatic reduction of the nitro group catalyzed by nitroreductase. Once activated, enzymes involved in the degradation of glucose and pyruvate are inhibited, accompanied by a decrease in bacterial activity [3].
Furazolidone (FZD), furaltadone (FTD), nitrofurantoin (NFT), and nitrofuranzone (NFZ) are the most commonly used NFs in animal production [4]. These drugs exhibited a short half-time in animals after ingestion and could be rapidly transferred to their respective metabolites: 3 -amino1,3-oxazolidin-2-one (AOZ), 1-amino-hydantoin (AHD), 3amino-5-(4-morpholinyl-methyl)-1,3-oxazolidin-2-one (AMOZ), and semicarbazide (SEM) [5-9]. These metabolites can bind to proteins to form stable structures and remain in the animal body for an extended period and can be released from the tissues only under acidic conditions $[8,9]$.

Toxicology research indicated that NFs and their metabolites are potentially hazardous substances, with possible carcinogenic, teratogenic, and mutagenic properties [10-13]. 
Metabolites of NFs (NFMs) usually exhibited much higher toxicity than their corresponding parent molecules and are hard to degrade even during steaming, baking, grinding, and microwave heating processes [14-16].

Due to their toxicity, many countries have banned NFs, as the European Union (EU) initiated in 1995 [17], followed by the USA (Federal Register 2002), China (Regulation of the Department of Agriculture of China 2002), and Korea (Food code 2004). After several years, the EU established the first minimum required performance limit (MRPL) for NFMs set at $1 \mu \mathrm{g} / \mathrm{kg}$ according to Decision No. 2003/181 [18]. More recently, the European Food Safety Authority (EFSA) published a scientific opinion on nitrofurans and their metabolites in food [19], which pushed the EU to set the reference points for action (RPAs) for these metabolites at $0.5 \mu \mathrm{g} / \mathrm{kg}$, consistent with the Commission Regulation (EU) 2019/1871 [20]. NFs are still being used illegally in animal treatment despite the stringent policy due to their low price and good therapeutic effect [21].

The analysis of nitrofuran residues in food is based on the detection of its metabolites [8, 22]. Enzyme-linked immunosorbent assay, flow injection, chemiluminescence, HPLC, and HPLC-MS were reported to be the most widely used methods [22-29]. HPLC-MS is considered the most efficient technique among these methods due to its reliability, sensitivity, and selectivity $[24,26,28]$. Although many HPLC-MS methods have been reported in recent years to detect nitrofuran derivatives in complex matrix foods (e.g., honey [26, 30-35], milk [34-38], meat [34, 35, 39-43], seafood [44, 45], and eggs [34, 46, 47]), there are still problems that need to be solved more or less. For example, a sample clean-up step, usually SPE, is typically required to eliminate matrix effects. However, the SPE method usually implies much more complex purification steps, including activation, washing, elution, etc. Also, if the sample is gelatinous or relatively viscous, it may clog the SPE column and be challenging to separate.

SPME is a relatively recent sample pretreatment technique integrating sampling, extraction, concentration, and injection in one step $[48,49]$. SPME exhibits many advantages, such as full process automation, avoidance of organic solvent consumption, and suitability for in situ and in vivo sampling. Due to its ultrahigh efficiency, SPME is receiving widespread attention from analysts in different fields, especially in routine laboratories and industrial applications [50-54]. The coated wooden tip is one SPME technology based on substrate-ESI and lately used for food safety analysis [55-58]. However, this method has a low ionization efficiency and poor reproducibility and is not easy to apply to complex food matrices, such as meat.

This study designed a crude, simple, inexpensive, easyto-prepare wooden-tip-based SPME device combined with HPLC-MS/MS to determine nitrofuran metabolite derivatives in complex foods. Compared to traditional SPE methods, this SPME technique can compress costs and reduce analysis time, efficiently facilitating the handling of viscous, colloidal complex samples while potentially highly automated. This established method was further validated in terms of limit of detections (LODs), limit of quantifications
(LOQs), and recoveries of each nitrofuran metabolite derivatives in pork, croaker, and honey. Ultimately, this method was used to evaluate real positive samples.

\section{Materials and Methods}

2.1. Materials and Chemicals. The external standards, including AOZ, AHD, AMOZ, and SEM, were purchased from Sigma-Aldrich (Germany). Isotopically labeled $\mathrm{AOZ}-\mathrm{d}_{4}$, AHD- $\mathrm{d}_{3}, A M O Z-\mathrm{d}_{5}$, SEM- $\mathrm{d}_{3}$, used as Internal Standards (ISs), and 2-nitrobenzaldehyde (2-NBA) were also bought from Sigma-Aldrich (Germany). All reference standards were more than $98 \%$ pure. A Milli-Q purification system (Millipore, USA) was used to produce deionized water. The PAN powder was obtained from Macklin (Shanghai, China) and Oasis HLB from Waters (Shanghai, China). Dimethyl sulfoxide (DMSO), dipotassium hydrogen phosphate, sodium hydroxide, ammonium acetate, formic acid, and concentrated hydrochloric acid were obtained from Kermel (Tianjin, China) with a purity higher than $98 \%$. HPLC grade ethyl acetate, n-hexane, methanol, acetonitrile, and isopropanol were purchased from Fisher (Shanghai, China). Medical cotton swabs to prepare PAN/HLB wooden tips were purchased from a local medical store in Weifang (China).

2.2. Standard Solutions. Standard solutions of NFMs were prepared by diluting individual stock solutions containing $100 \mathrm{mg} / \mathrm{L}$ of each standard dissolved in methanol $(\mathrm{MeOH})$. The solutions of ISs were prepared by mixing AOZ- $\mathrm{d}_{4}$, AHD- $\mathrm{d}_{3}, A M O Z-\mathrm{d}_{5}$, and SEM- $\mathrm{d}_{3}$ in methanol at a concentration of $100 \mathrm{mg} / \mathrm{L}$. Then, these two standard solutions were mixed in an intermediate solution at $1 \mu \mathrm{g} / \mathrm{mL}$. A series of working solutions of NFMs and their ISs were prepared by diluting the intermediate solution with methanol. These solutions were cooled to $-20^{\circ} \mathrm{C}$ in a freezer immediately after preparation. The 2-NBA solution was freshly prepared at a concentration of $50 \mathrm{mM}$ in methanol.

\subsection{Preparation of PAN/HLB-Coated Wooden-Tip-Based} $S P M E$. An amount of $7 \mathrm{~g}$ of PAN powder was dissolved in $100 \mathrm{~mL}$ of DMF with constant stirring at room temperature to ensure uniform dissolution. An amount of $1 \mathrm{~g}$ HLB particles $(30 \mu \mathrm{m})$, previously obtained by ball mill grinding Oasis HLB at $240 \mathrm{rpm}$ for 2 hours, was mixed with a $10 \mathrm{~mL}$ PAN solution to obtain a PAN-HLB slurry. The mixture was then shaken and blended on an oscillator at $1800 \mathrm{rpm}$ for 12 hours to provide a sufficiently homogeneous combination of particles. The cotton from the tip of the medical swab was removed, and the wooden stick was dipped into the PANHLB slurry to a depth of about $1 \mathrm{~cm}$, making the glue evenly coated on the wooden tip, and then dipped and coated it again after drying slightly. The wooden tip was washed twice in a solvent solution (methanol/isopropanol/acetonitrile, $50: 25: 25$ ) by shaking at $1500 \mathrm{rpm}$ for a total of $3 \mathrm{~min}$ to remove residues. Scanning electron microscopy (JSM-6510, JOEL, Japan) was used to examine the surface morphology of the SPME probe. 
2.4. Sample Preparation. Muscle samples from meat or aquaculture products were minced and homogenized and stored at $-20^{\circ} \mathrm{C}$ until use. Honey samples were stored under dry conditions in the dark at $4^{\circ} \mathrm{C}$. For sample preparation, $3 \mathrm{~g}$ of the homogenized sample (accurate to $0.01 \mathrm{~g}$ ) was weighed, placed into a $50 \mathrm{~mL}$ polypropylene centrifuge tube, and spiked with $30 \mu \mathrm{L}$ of $0.1 \mu \mathrm{g} / \mathrm{mL}$ of ISs (AOZ- $\mathrm{d}_{4}, \mathrm{AHD}-\mathrm{d}_{3}$, AMOZ- $\mathrm{d}_{5}$, and SEM- $\mathrm{d}_{3}$ ). Then, $17 \mathrm{~mL}$ of $0.125 \mathrm{~mol} / \mathrm{L}$ hydrochloric acid and $1.0 \mathrm{~mL}$ of 2-NBA solution were added, homogenized for $1 \mathrm{~min}$, and kept in a constant temperature shaker at $37^{\circ} \mathrm{C}$ for $16 \mathrm{~h}$. The sample was centrifuged at $10000 \mathrm{r} / \mathrm{min}$ for $10 \mathrm{~min}$, and $10 \mathrm{~mL}$ of the supernatant was taken and moved into a $20 \mathrm{~mL}$ polypropylene centrifuge tube. Subsequently, $1 \mathrm{ml}$ of the dipotassium hydrogen phosphate solution was added to the test tube and the $\mathrm{pH}$ was adjusted to $7.2-7.4$ with $1 \mathrm{~mol} / \mathrm{L}$ sodium hydroxide solution and $0.1 \mathrm{~mol} / \mathrm{L}$ aqueous hydrochloric acid solution.

2.5. Wooden-Tip-Based SPME Procedure. The wooden-tipbased SPME probe was first soaked in a methanol/water mixture for pretreatment $\left(\mathrm{MeOH} / \mathrm{H}_{2} \mathrm{O}, 50: 50\right)$ to activate the HLB coating, then dropped into the sample solution, and shaken with a speed of $1800 \mathrm{rpm}$ for $2 \mathrm{~min}$ on a lab shaker at the room temperature. After this, the tip was picked up and placed into a centrifuge tube containing $5 \mathrm{~mL}$ of water, vibrated at $1800 \mathrm{rpm}$ for $2 \mathrm{~min}$. Then, the tip was collected and transferred into a centrifuge tube containing $5 \mathrm{~mL}$ of ethyl acetate and oscillated at the same speed for $3 \mathrm{~min}$. The extract was evaporated under nitrogen at about $50^{\circ} \mathrm{C}$ until dryness and then redissolved in $500 \mu \mathrm{L}$ of a mixture of methanol/ $0.1 \%$ formic acid aqueous solution $(10: 90 ; \mathrm{v}: \mathrm{v})$. Finally, the sample was filtered at $0.2 \mu \mathrm{m}$ and transferred into a microvial of $300 \mu \mathrm{L}$ adapted to the injector.

2.6. LC-MS/MS Analysis. Analysis of all samples was performed on the AB Science Qtrap 5500 system equipped with a Waters UPLC (with a binary pump, an autosampler, and a ZORBAX Eclipse Plus C18 column $(1.8 \mu \mathrm{m}, 2.1 \times 50 \mathrm{~mm}))$. During operation, the temperature of the column oven was kept constant at $40^{\circ} \mathrm{C}$. With a mobile phase consisting of $10 \mathrm{mM}$ ammonium acetate and $0.1 \%$ formic acid in water (eluent A) and methanol (eluent B), the analytes were separated at a flow rate of $0.3 \mathrm{~mL} / \mathrm{min}$. Starting with $10 \%$ of eluent B, the gradient increased linearly to $90 \%$ in 3 minutes, then was maintained for 2 minutes, and returned to the original conditions in 1.5 minutes. Later, a one-minute reequilibration was required. The injection volume was $10 \mu \mathrm{L}$. A triple quadrupole mass spectrometer (AB Science Qtrap 5500) was used to quantify target compounds. Data collection was monitored using the Analyst 1.6.2 software, and the optimized source parameters are as follows:

Spray voltage of $5.5 \mathrm{kV}$

Vaporizer temperature of $550^{\circ} \mathrm{C}$

Curtain gas pressure of $35 \mathrm{psi}$

Ion-source gas 1 (nebulizer gas) pressure of $55 \mathrm{psi}$

Ion-source gas 2 (turbo gas) pressure of $50 \mathrm{psi}$
With positive ESI, NFMs were detected in the MRM mode. Table 1 displays the compound-dependent parameters.

2.7. Method Validation. The proposed method was validated according to the Chinese National Standard (GB/T 274042008) [59]. The validation parameters include linearity, accuracy, precision, limit of detection (LOD), limit of quantification (LOQ), and recovery. The analytical signal was the ratio of peak areas of analytes to the corresponding internal standards.

Calibration curves were constructed by diluting the NFM standard at five concentrations $(2.0,4.0,8.0,16.0$, and $20.0 \mu \mathrm{g} / \mathrm{L}$, containing $4 \mu \mathrm{g} / \mathrm{L}$ ISs $\left(\mathrm{AOZ}-\mathrm{d}_{4}, \mathrm{AHD}-\mathrm{d}_{3}\right.$, AMOZ$\mathrm{d}_{5}$, and $\left.S E M-\mathrm{d}_{3}\right)$ ) with the mobile phase. Linearity was determined based on the correlation coefficients of the calibration curves. Instrument response versus concentration plots were constructed for each analyte, and linear equations and correlation coefficients were calculated by linear regression analysis. The range of each analyte used for its calibration curves is listed in Table 2. The IS calibration method was used in this study to correct each substance's matrix effects and isolate their contribution to the actual sample matrix [60].

The accuracy was assessed by adding three levels of NFM standards $(0.5,1.0$, and $5 \mu \mathrm{g} / \mathrm{kg})$ and ISs to the samples and calculating their recoveries. Precision was calculated by performing intraday (repeatability) and interday (reproducibility) studies and expressed as relative standard deviation (RSD). The intraday precision was determined using the same concentration levels $(0.5,1.0$, and $5 \mu \mathrm{g} / \mathrm{kg})$, and 6 parallel tests were conducted for each concentration level, whereas interday precision was studied, spiking 6 samples at $0.5,1.0$, and $5 \mu \mathrm{g} / \mathrm{kg}$ in different days. Selectivity of the method is achieved by using control blank samples. LODs and LOQs of the method correspond to the signal-to-noise ratios of 3 and 10, respectively.

\section{Results and Discussion}

3.1. Design Principle and Characterization of PAN/HLBCoated Wooden-Tip-Based SPME. The procedure of wooden-tip-based SPME probe combined with LC-MS/MS for the detection of complex foods is shown in Figure 1. Morphological characterization of the PAN/HLB-coated wooden tip was performed via scanning electron microscopy analysis, as illustrated in Figure 2. It clearly shows that the surface of the wooden tip wrapped with PAN/HLB (Figure 2(c)) coating is covered with lots of "bubbles," different from the tip itself (Figure 2(a)) and the PANcovered tip (Figure 2(b)), suggesting an overcoating of HLB particles.

3.2. Optimization of Wooden Tip Coating Thickness. When dealing with the SPME technology, the thickness of the extracted phase is crucial because this characteristic of the equipment will be a deciding factor. Typically, a thicker coating would adsorb more target compounds and improve 
TABLE 1: Mass spectrometry parameters for the analysis of 2-NP-NFMs and their ISs.

\begin{tabular}{lcccc}
\hline Analyte & Precursor ion $(\mathrm{m} / z)$ & Product ion $(\mathrm{m} / z)$ & DP $(\mathrm{V})$ & 80 \\
2-NP-SEM & 209.1 & $166.2^{*}, 192$ & 117 & 14,16 \\
2-NP-AOZ & 236.1 & $134.2^{*}, 104$ & 117 & 17,31 \\
2-NP-AOZ-d & 240.2 & 134 & 120 & 20 \\
2-NP-AHD & 249.1 & $104.1^{*}, 134$ & 100 & 17,27 \\
2-NP-AHD-d & 252.1 & $291.1^{*}, 262.2$ & 80 & 17 \\
2-NP-AMOZ & 335.2 & 296.1 & 80 & 17,23 \\
2-NP-AMOZ-d & 340.2 & & 20 \\
\hline
\end{tabular}

*Quantitation ion.

TABLE 2: Linear range, correlation coefficient, and calibration curves of 2-NP-NFMs.

\begin{tabular}{lccc}
\hline Analyte & Linear range $(\mu \mathrm{g} / \mathrm{L})$ & Calibration equation & Correlation coefficient $\left(r^{2}\right)$ \\
\hline 2-NP-AOZ & $0.25-2.5$ & $y=0.538 x-0.0239$ & 0.9998 \\
2-NP-AHD & $0.25-2.5$ & $y=0.198 x-0.0114$ & 0.9997 \\
2-NP-AMOZ & $0.25-2.5$ & $y=0.457 x+0.0204$ & 0.9977 \\
2-NP-SEM & $0.25-2.5$ & $y=2.05 x-0.0559$ & 0.9997 \\
\hline
\end{tabular}

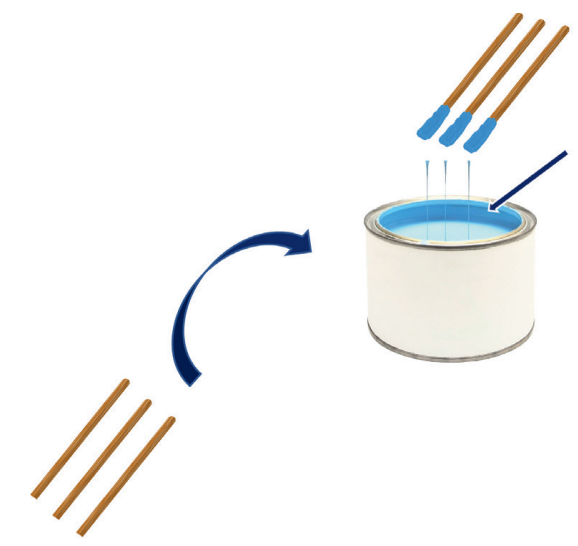

PAN/HLB coated wooden-tips

PAN/HLB

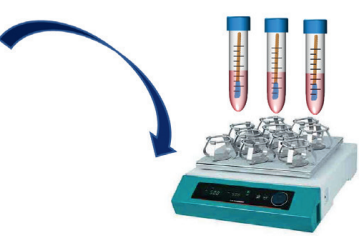

Absorption and purification step

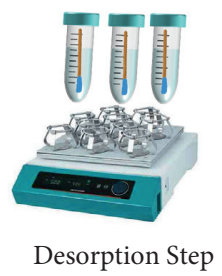

HPLC-MS/MS

FIGURE 1: Schematic diagram of the procedure of wooden-tip-based SPME probe combined with LC-MS/MS for the detection of complex foods.

detection sensitivity. However, overcoating can make the preparation of SPME devices more difficult while causing material waste. Therefore, it is essential to find the ideal coating thickness. In order to investigate the effect of coating thickness on method response when applying to the HPLCMS/MS approach, the wooden tip was tested, which had one layer, two layers, and three layers of a PAN-HLB coating applied, corresponding to 2.35, 4.71, and $11.18 \mathrm{mg}$ of the sorbent weight. Each coating thickness was analyzed in triplicate, with an NFMs standard concentration of $0.1 \mathrm{mg} /$ $\mathrm{mL} 200 \mu \mathrm{L}$ spiked in pork and a shaking extraction time of 3 min. As shown in Figure 3, the highest mass spectral response values for the target compounds were obtained for the tips with two layers, and the response values decreased when the coating thickness increased to three layers. The slight signal drops may be because as the coating thickness increases, the uniformity decreases, causing the loss of some binding sites of the HLB to be concealed. This result shows that only about $5 \mathrm{mg}$ of PAN/HLB coating (2 layers) is required to meet the detection needs of NFMs, which can largely cut the analysis cost compared with the current widely applied SPE cartridge (contains typically 30-500 mg HLB). Two layers of PAN-HLB coatings were employed for all further experimentation.

3.3. Optimization of Extraction Time. The derivatization conditions of nitrofurans have been discussed in detail in many articles $[33,40,45,61,62]$. Most of them suggest that a temperature of $37^{\circ} \mathrm{C}$ and a $\mathrm{pH}$ value of about 7.0 are optimal. 


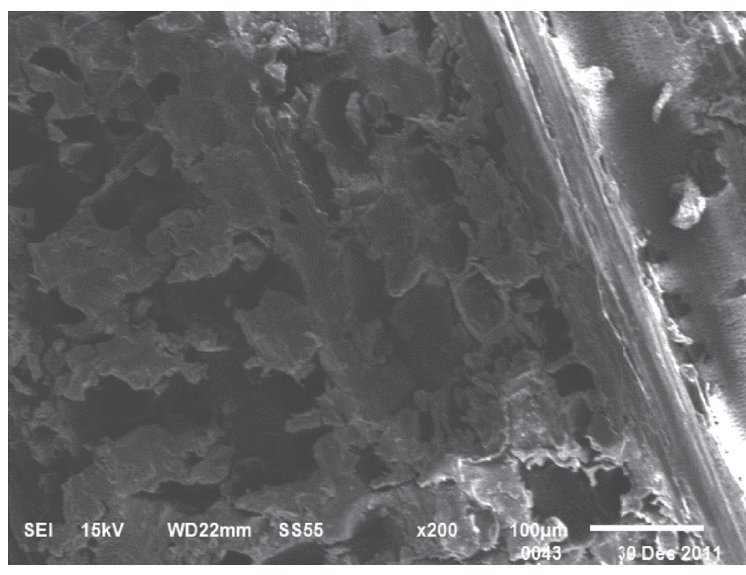

(a)

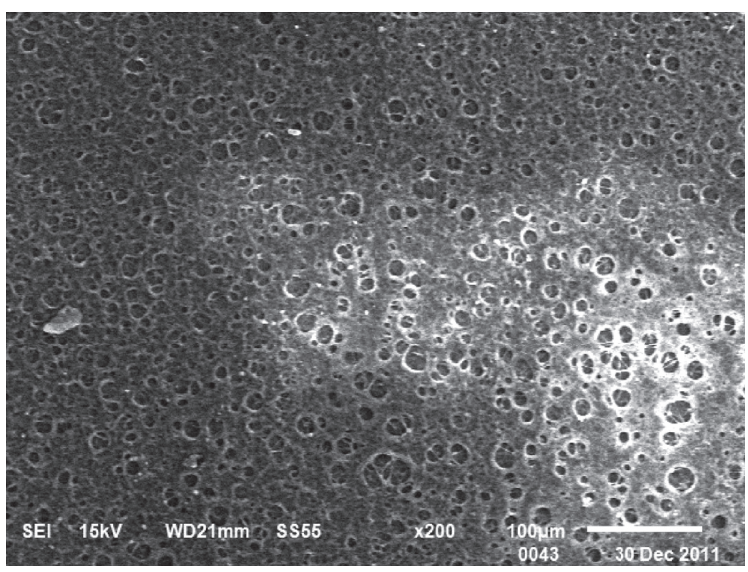

(b)

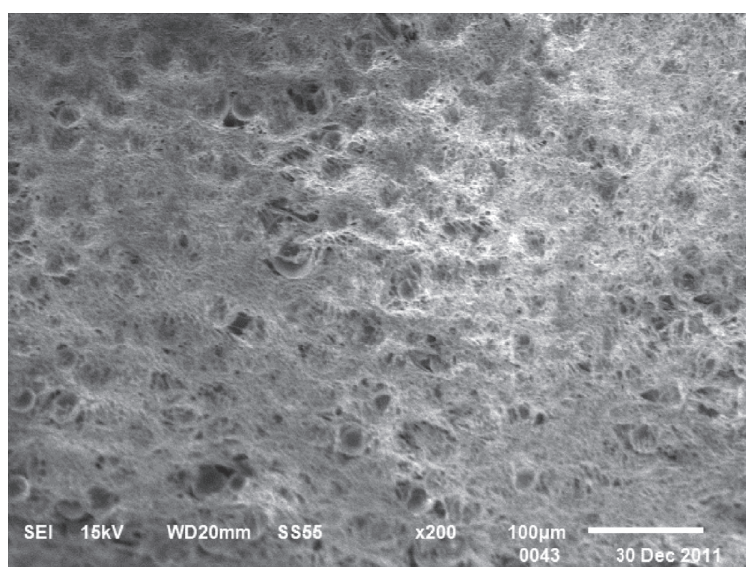

(c)

FIGURE 2: Scanning electron microscopy images of (a) wooden tip, (b) PAN-coated wooden tip, and (c) PAN/HLB-coated wooden tip.

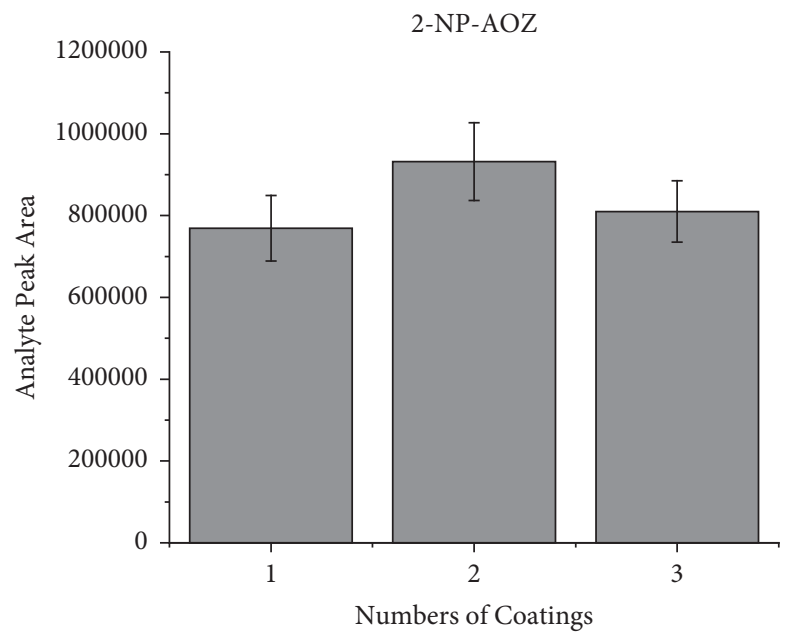

(a)

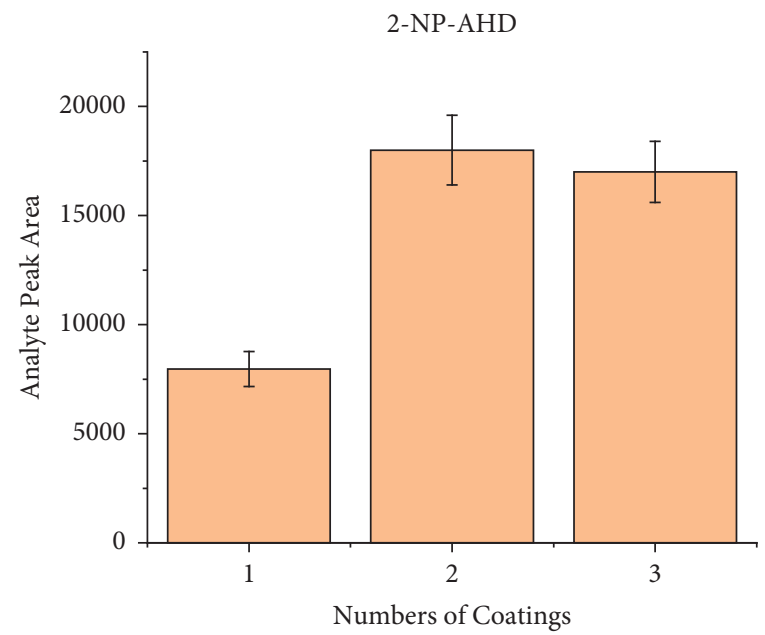

(b)

Figure 3: Continued. 


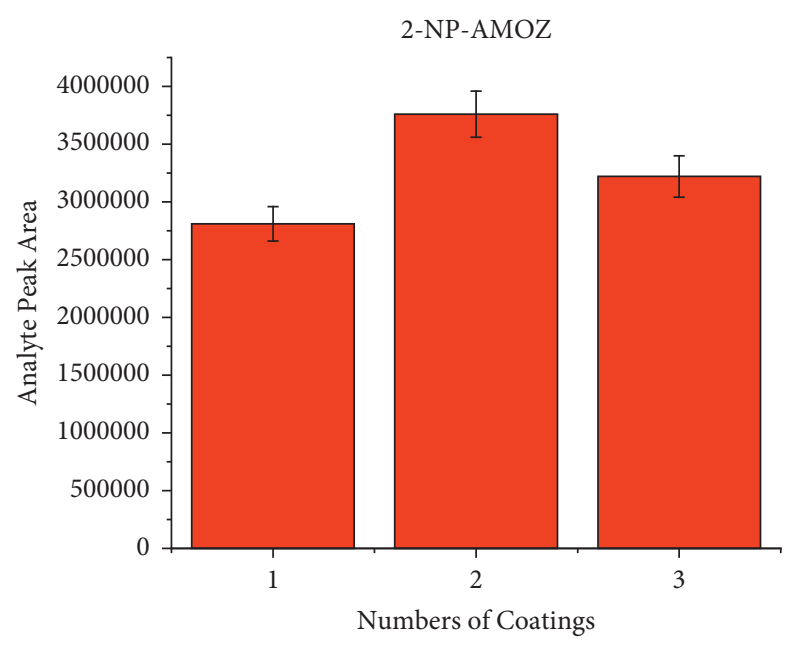

(c)

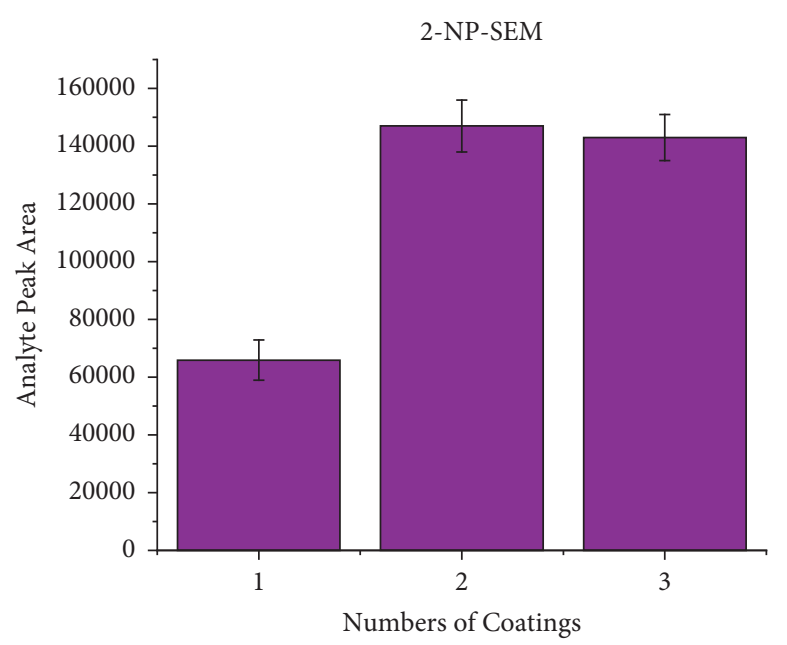

(d)

FIgURE 3: Effect of extraction phase thickness on the SPME efficiency.

Therefore, the present paper discusses the derivatization conditions, and the literature reports are directly adopted. Extraction time is an important factor in the dynamic equilibrium process of SPME, and different extraction times (i.e., $2 \mathrm{~min}, 5 \mathrm{~min}, 10 \mathrm{~min}$, and $20 \mathrm{~min}$ ) were investigated on the influences. Each experiment was investigated by analyzing pork spiked with $40 \mu \mathrm{L}$ of the NFM standard $(0.1 \mu \mathrm{g} /$ $\mathrm{mL}$ ) in triplicate. As shown in Figure 4, the response signal peak area increased from $30 \mathrm{~s}$ to $2 \mathrm{~min}$ and then remained relatively constant, indicating that the extraction equilibrium was reached. Therefore, the results indicated that the extraction process could be completed in a short time ( $2 \mathrm{~min}$ ). Consequently, $2 \mathrm{~min}$ was selected as the extraction time for further experiments. It is worth mentioning that, unlike the traditional nonautomated SPE purification process, here, we use a lab shaker that allows semiautomated operation and simultaneous processing of dozens of samples, significantly improving efficiency.

3.4. Reusability of the PAN/HLB-Coated Wooden Tip. To evaluate the reusability of the PAN/HLB-coated wooden tip, 5 cycles of adsorption experiment were performed by analysis of pork spiked with $40 \mu \mathrm{L}$ of the NFM standard (concentration of $0.1 \mu \mathrm{g} / \mathrm{mL}$ ). Each cycle was carried out by triple times. The binding capacity of 5 cycles for the target molecule is shown in Figure 5. During the 5-cycle period, each cycle was accompanied by a decrease in the chromatographic signal peak, which was attributed to decreased adsorption capacity due to the loss of binding sites. After 5 cycles, the wooden-tipbased SPME probe reached more than $70 \%$ of the first adsorption capacity for 2-NP-AOZ, 2-NP-AHD, 2-NP-AMOZ, and over 50\% 2-NP-SEM. Based on these results, the PAN/ HLB-coated wooden tip demonstrates good regeneration performance and could be recycled several times.
3.5. Method Validation. As shown in Table 3, selectivity, specificity, and sensitivity were evaluated with good results (including at a concentration of $0.5 \mu \mathrm{g} / \mathrm{kg}$ ) in compliance with EU regulation 2002/657/EC. The signal-to-noise ratio $(\mathrm{S} / \mathrm{N})$ was determined by comparing the signal with the lowest concentration of the target analyte and the blank sample. The LODs and LOQs of the four NFMs were obtained by 3 and 10 times the $S / N$, respectively. For the three different food matrices (pork, croaker, and honey), the values of LOD and LOQ were, respectively, ranging from 0.011 to 0.123 and 0.033 to $0.369 \mu \mathrm{g} / \mathrm{kg}$ (pork), 0.009 to 0.112 and 0.027 to $0.339 \mu \mathrm{g} / \mathrm{kg}$ (croaker), and 0.010 to 0.131 and 0.030 to $0.293 \mu \mathrm{g} / \mathrm{kg}$ (honey). It can be seen that the LOQ of the method is lower than the MRPL of $1.0 \mu \mathrm{g} / \mathrm{kg}$ specified by the EU. Accuracy and precision were determined by each recovery and percentage root square deviation (\%RSD) and by peak area at three concentration levels $(0.5,1.0$, and $5 \mu \mathrm{g} /$ $\mathrm{kg})$. The average recovery of all NFM derivatives ranges from 97.4-140.3\% (pork), 87.5-112.7\% (croaker), and 98.6-109.0\% (honey), as Table 3 summarized. It can be seen (Table 3) that intraday and interday precisions were lower than $10 \%$ for the three levels assayed. Typical multiple reaction monitoring (MRM) chromatograms of a spiked sample are shown in Figure 6.

3.6. Analysis of Real Samples. In order to test the accuracy of the method on the actual positive samples, the method established in this paper was applied to test the proficiency testing samples provided by China National Accreditation Service for Conformity Assessment (CNAS) for the determination of nitrofurans in chicken meat (no. ACAS-PT1048), and the results are as shown in Table 4. It is shown that our method is closer to the true values than the China national GB standard method (GB/T 20752-2006, 


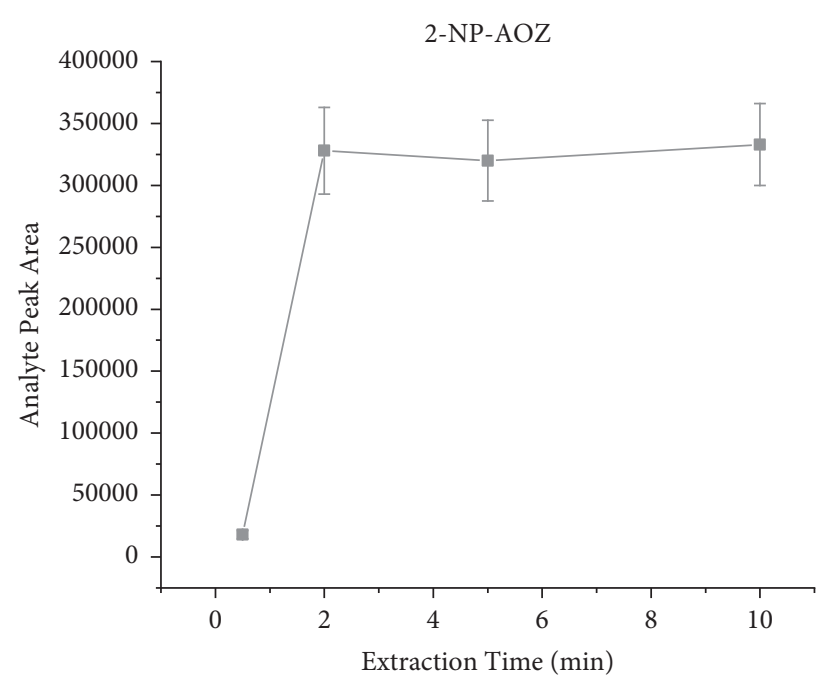

(a)

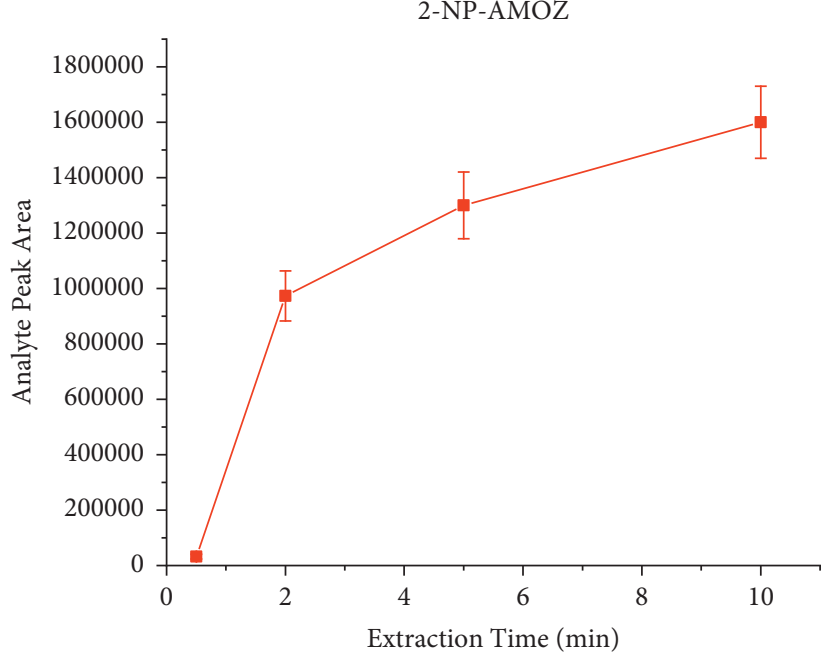

(c)

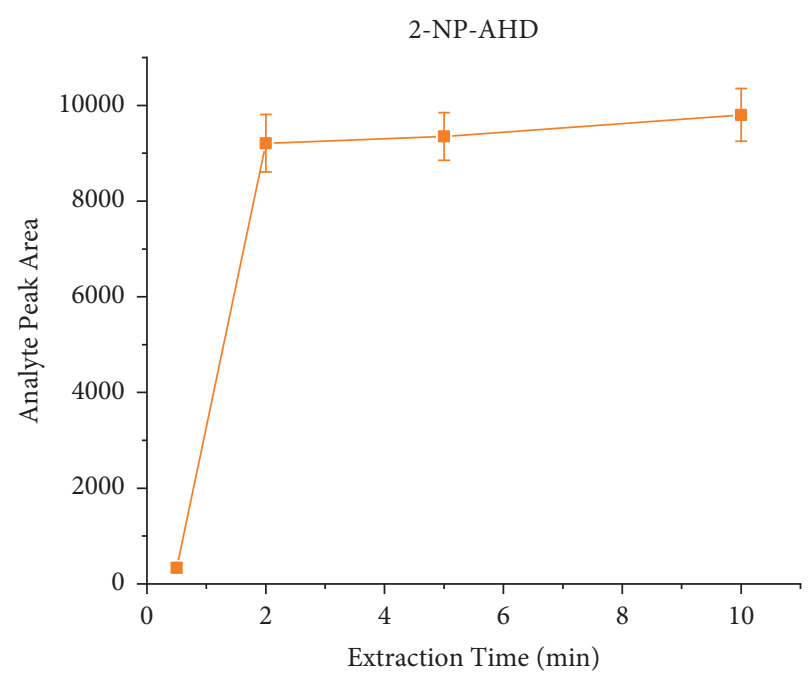

(b)

2-NP-SEM

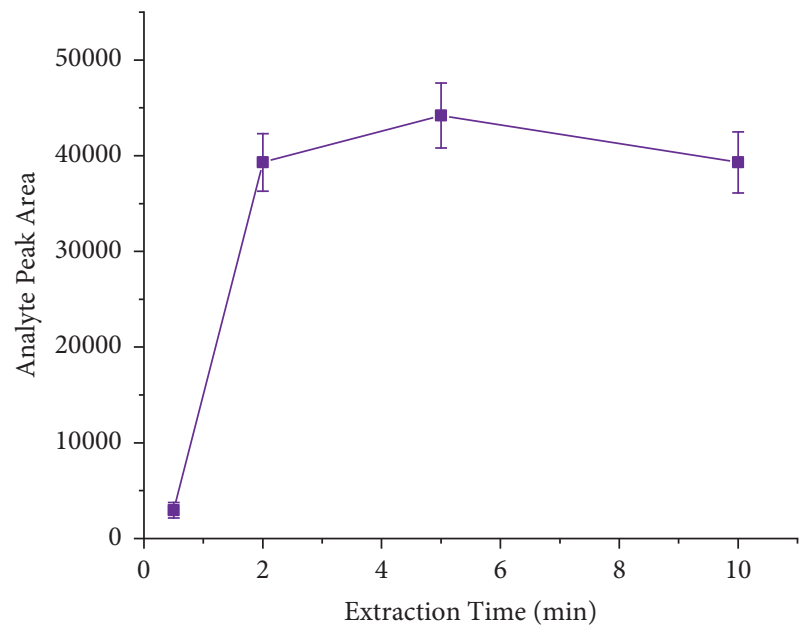

(d)

FIGURE 4: Effect of extraction time on the SPME efficiency.

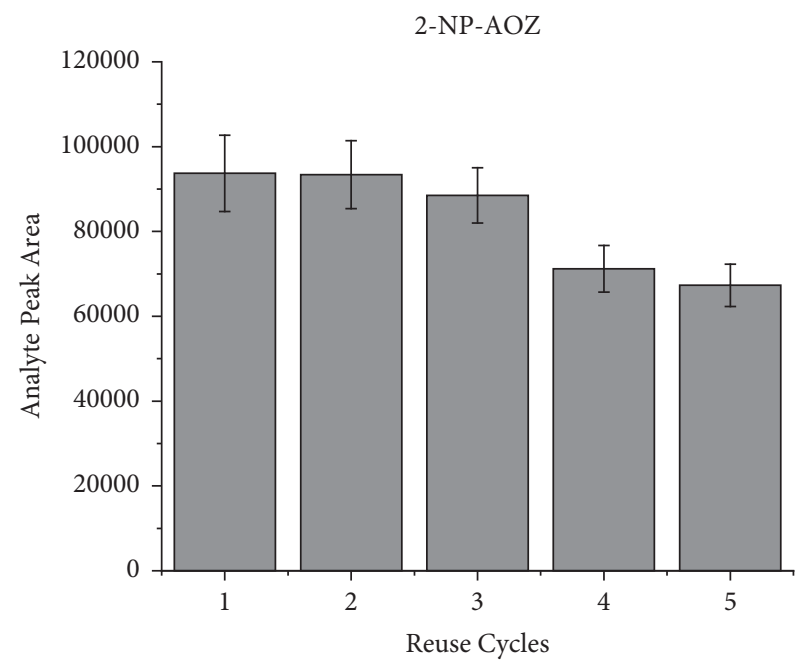

(a)

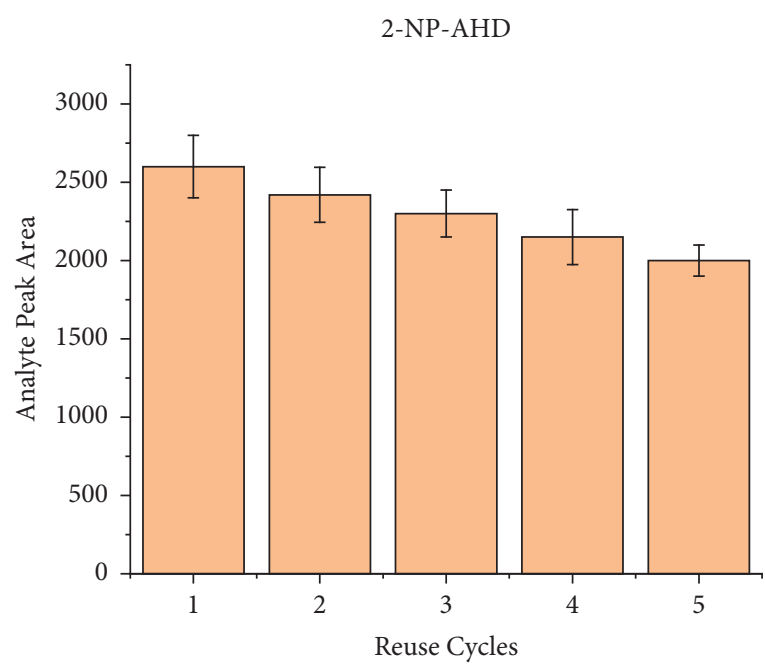

(b)

Figure 5: Continued. 


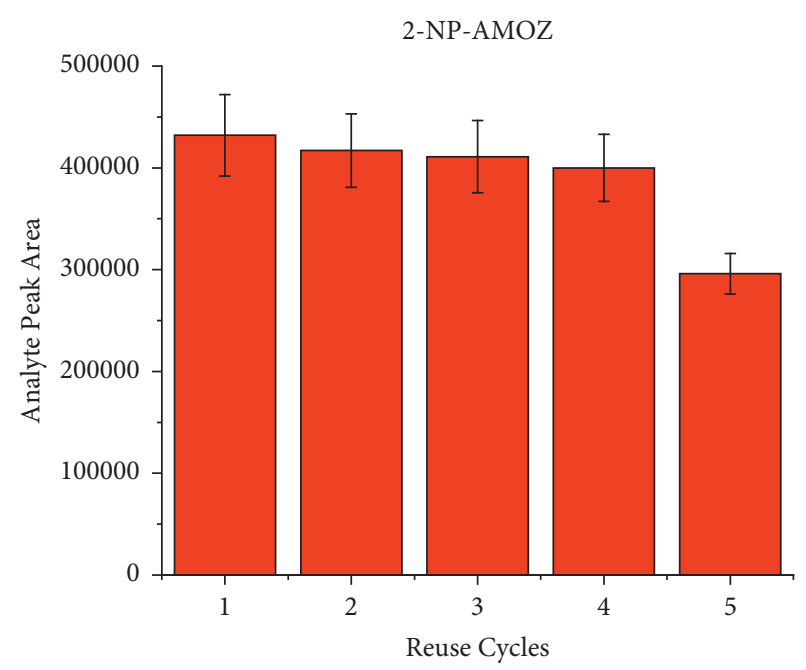

(c)

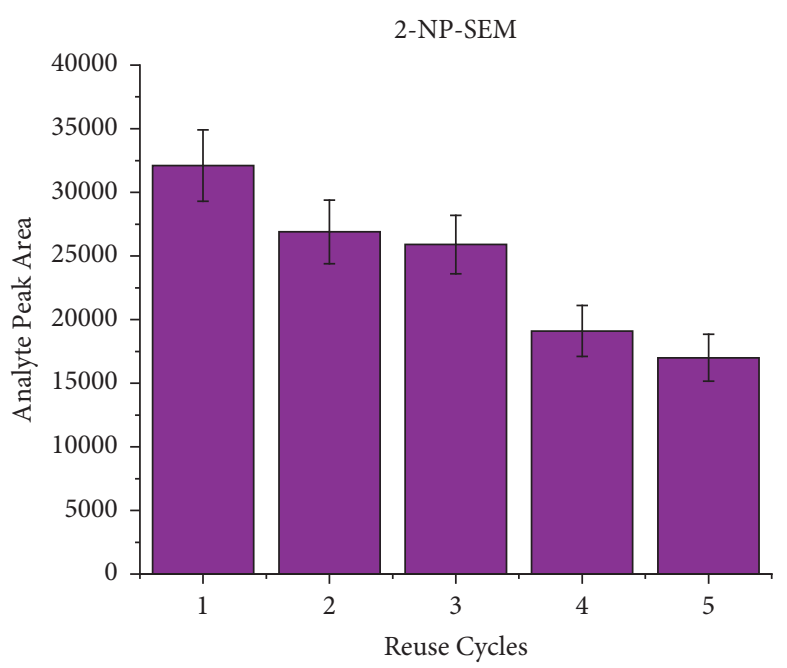

(d)

Figure 5: Regeneration of the SPME for five reuse cycles.

TABLE 3: Corrected intraday and interday accuracies and precision for complex matrix spiked with working standard solution $(n=6)$.

\begin{tabular}{|c|c|c|c|c|c|c|c|}
\hline Analyte & Matrix & $\begin{array}{l}\text { Spiked level } \\
(\mu \mathrm{g} / \mathrm{kg})\end{array}$ & $\begin{array}{c}\text { Intraday series } \\
\text { (\% RSD) }\end{array}$ & $\begin{array}{c}\text { Interday series } \\
(\% \text { RSD })\end{array}$ & $\begin{array}{c}\text { LOD } \\
(\mu \mathrm{g} / \mathrm{kg})\end{array}$ & $\begin{array}{c}\text { LOQ } \\
(\mu \mathrm{g} / \mathrm{kg})\end{array}$ & Recovery (\%) \\
\hline \multirow{3}{*}{ 2-NP-AOZ } & \multirow{15}{*}{ Pork } & 0.5 & 6.98 & 8.14 & \multirow{3}{*}{0.043} & \multirow{3}{*}{0.129} & 109.5 \\
\hline & & 1.0 & 3.69 & 5.29 & & & 104.3 \\
\hline & & 5.0 & 5.27 & 3.73 & & & 103.0 \\
\hline \multirow{3}{*}{ 2-NP-AHD } & & 0.5 & 8.14 & 7.66 & \multirow{3}{*}{0.072} & \multirow{3}{*}{0.216} & 97.4 \\
\hline & & 1.0 & 6.03 & 8.69 & & & 98.2 \\
\hline & & 5.0 & 5.91 & 4.78 & & & 99.7 \\
\hline \multirow{3}{*}{ 2-NP-AMOZ } & & 0.5 & 3.80 & 7.08 & \multirow{3}{*}{0.011} & \multirow{3}{*}{0.033} & 102.6 \\
\hline & & 1.0 & 5.78 & 6.42 & & & 101.9 \\
\hline & & 5.0 & 5.91 & 4.07 & & & 102.5 \\
\hline \multirow{3}{*}{ 2-NP-SEM } & & 0.5 & 9.41 & 8.11 & \multirow{3}{*}{0.123} & \multirow{3}{*}{0.369} & 108.1 \\
\hline & & 1.0 & 8.67 & 5.25 & & & 103.2 \\
\hline & & 5.0 & 6.53 & 6.29 & & & 99.6 \\
\hline \multirow{3}{*}{ 2-NP-AOZ } & & 0.5 & 3.83 & 4.18 & \multirow{3}{*}{0.036} & \multirow{3}{*}{0.109} & 112.7 \\
\hline & & 1.0 & 4.95 & 3.53 & & & 105.5 \\
\hline & & 5.0 & 3.04 & 3.11 & & & 99.1 \\
\hline \multirow{3}{*}{ 2-NP-AHD } & & 0.5 & 7.64 & 6.47 & \multirow{3}{*}{0.060} & \multirow{3}{*}{0.180} & 105.6 \\
\hline & & 1.0 & 6.05 & 6.14 & & & 103.2 \\
\hline & & 5.0 & 8.12 & 5.89 & & & 101.5 \\
\hline \multirow{4}{*}{ 2-NP-AMOZ } & & 0.5 & 4.03 & 5.86 & \multirow{3}{*}{0.009} & \multirow{3}{*}{0.027} & 96.5 \\
\hline & & 1.0 & 3.87 & 7.55 & & & 97.3 \\
\hline & & 5.0 & 4.53 & 6.34 & & & 98.9 \\
\hline & & 0.5 & 6.51 & 7.34 & \multirow{3}{*}{0.112} & \multirow{3}{*}{0.337} & 87.5 \\
\hline \multirow[t]{3}{*}{ 2-NP-SEM } & Croaker & 1.0 & 5.37 & 6.53 & & & 88.3 \\
\hline & & 5.0 & 6.72 & 8.07 & & & 92.4 \\
\hline & & 0.5 & 3.87 & 7.03 & \multirow{3}{*}{0.035} & & 103.4 \\
\hline \multirow[t]{3}{*}{ 2-NP-AOZ } & & 1.0 & 2.79 & 8.14 & & 0.105 & 105.2 \\
\hline & & 5.0 & 5.02 & 5.31 & & & 102.4 \\
\hline & & 0.5 & 2.91 & 5.88 & & & 109.0 \\
\hline 2-NP-AHD & & 1.0 & 2.06 & 3.74 & 0.131 & 0.293 & 99.7 \\
\hline & & 5.0 & 4.72 & 5.96 & & & 104.8 \\
\hline & & 0.5 & 4.52 & 6.85 & & & 100.4 \\
\hline 2-NP-AMOZ & & 1.0 & 2.36 & 5.92 & 0.010 & 0.030 & 101.2 \\
\hline & & 5.0 & 3.18 & 6.25 & & & 99.3 \\
\hline & Honey & 0.5 & 2.51 & 4.14 & & & 104.7 \\
\hline 2-NP-SEM & & 1.0 & 3.77 & 2.36 & 0.063 & 0.189 & 100.5 \\
\hline & & 5.0 & 2.09 & 3.53 & & & 98.6 \\
\hline
\end{tabular}




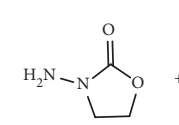<smiles>O=Cc1ccccc1[N+](=O)[O-]</smiles><smiles>O=C1OCCN1/N=C/c1ccccc1[N+](=O)[O-]</smiles>

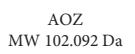
2-Nitrobenzaldehyde
MW 152.120 Da MW 102.092 Da<smiles>NN1CC(=O)NC1=O</smiles><smiles>O=Cc1ccccc1[N+](=O)[O-]</smiles>

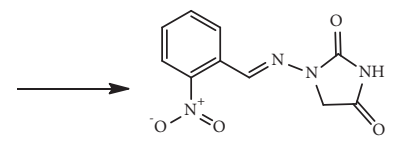
AHD
MW 115.091 Da

2-Nitrobenzaldehyde MW 152.120 Da<smiles>NN1CC(CN2CCOCC2)OC1=O</smiles><smiles>O=Cc1ccccc1[N+](=O)[O-]</smiles><smiles>CCCC</smiles>
MW 248.195 D<smiles>NNC(N)=O</smiles>

2-NP-AMOZ
MW 334.327 Da
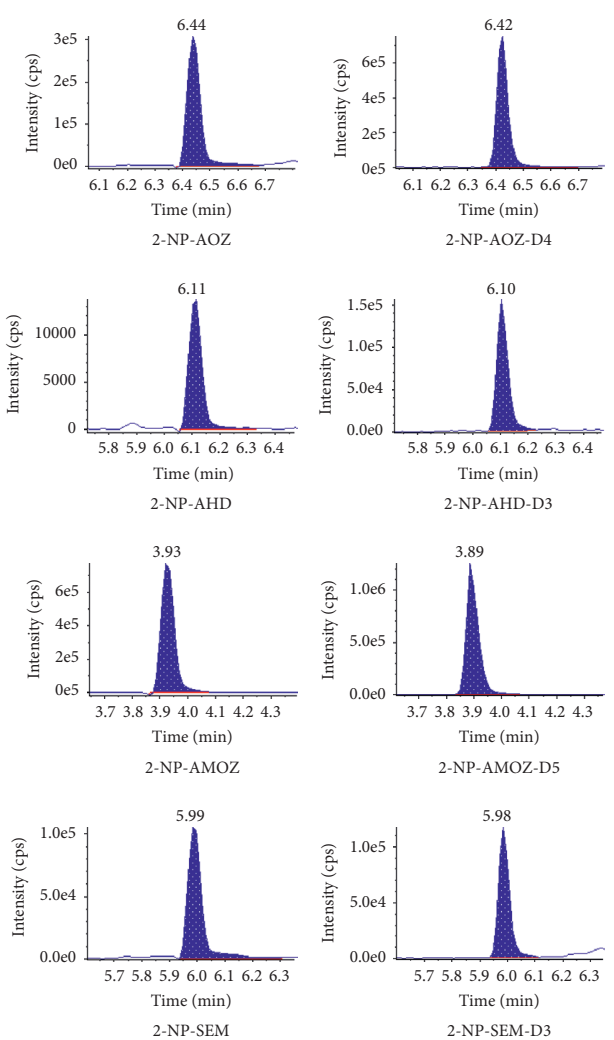

Figure 6: Chromatograms of NFMs $(0.5 \mu \mathrm{g} / \mathrm{kg})$ and the ISs in the pork samples.

TABLE 4: Results of NFM determination in CNAS proficiency testing samples measured by the GB method and wooden tip method.

\begin{tabular}{|c|c|c|c|c|c|}
\hline \multirow[b]{2}{*}{ Analyte } & \multirow{2}{*}{ Sample no. } & Conce & ntration $(\mu \mathrm{g} / \mathrm{kg})$ & \multirow{2}{*}{ True value $(\mu \mathrm{g} / \mathrm{kg})$} & \multirow[b]{2}{*}{$Z$ value (only the results of the GB method are counted) } \\
\hline & & GB method & Wooden tip method & & \\
\hline \multirow{2}{*}{$\mathrm{AOZ}$} & $20-\mathrm{N} 483$ & 10.6 & 12.9 & 17.0 & -1.1 \\
\hline & 20-J996 & 11.6 & 14.2 & 17.0 & -1.0 \\
\hline \multirow{2}{*}{ AMOZ } & $20-\mathrm{N} 483$ & 30.3 & 33.6 & 39.0 & -0.5 \\
\hline & 20-J996 & 32.6 & 35.7 & 39.0 & -0.4 \\
\hline
\end{tabular}

employing SPE purification step) [63], meaning that the presented method can be used to replace the national standard method in real sample testing.

\section{Concluding Remarks}

A rough, cheap, easy-made wooden-tip-based SPME probe was developed, optimized, and validated to simultaneously determine 4 NFM derivatives in complex food matrices by LC-MS/MS. The present method is less time-consuming and less expensive than the traditional SPE clean-up method and achieved desirable reliability, sensitivity, and simplicity in the analysis process. Additionally, the developed PAN/HLBcoated wooden tip LC-MS/MS method provided good repeatability and reproducibility in a deficient concentration level. Finally, the method can be successfully applied to the analysis of real positive samples.

\section{Data Availability}

The data used to support the findings of this study are included within the article.

\section{Conflicts of Interest}

The authors declare that they have no conflicts of interest.

\section{Authors' Contributions}

Xiaoming Gong and Kai Li contributed equally to this work.

\section{Acknowledgments}

This work was financially supported by General Administration of Customs P. R. China, grant no. 2020HK201.

\section{References}

[1] T. Tang, F. Wei, X. Wang et al., "Determination of semicarbazide in fish by molecularly imprinted stir bar sorptive extraction coupled with high performance liquid chromatography," Journal of Chromatography B, Analytical Technologies in the Biomedical and Life Sciences, vol. 1076, pp. 8-14, 2018. 
[2] M. Vass, K. Hruska, and M. Franek, "Nitrofuran antibiotics: a review on the application, prohibition and residual analysis," Veterinarni Medicina, vol. 53, no. 9, pp. 469-500, 2008.

[3] F. Ramos, L. Santos, and J. Barbosa, "Nitrofuran veterinary drug residues in chicken eggs," in Egg Innovations and Strategies for Improvements, P. Y. Hester, Ed., Academic Press, Cambridge, MA, USA, pp. 457-464, 2017.

[4] A. K. Sarmah, M. T. Meyer, and A. B. A. Boxall, "A global perspective on the use, sales, exposure pathways, occurrence, fate and effects of veterinary antibiotics (VAs) in the environment," Chemosphere, vol. 65, no. 5, pp. 725-759, 2006.

[5] J. J. Laurensen and J. F. M. Nouws, "Simultaneous determination of nitrofuran derivatives in various animal substrates by high-performance liquid chromatography," Journal of Chromatography A, vol. 472, pp. 321-326, 1989.

[6] J. F. M. Nouws and J. Laurensen, "Postmortal degradation of furazolidone and furaltadone in edible tissues of calves," Veterinary Quarterly, vol. 12, no. 1, pp. 56-59, 1990.

[7] K. M. Cooper and D. G. Kennedy, "Stability studies of the metabolites of nitrofuran antibiotics during storage and cooking," Food Additives and Contaminants, vol. 24, no. 9, pp. 935-942, 2007.

[8] P.-S. Chu and M. I. Lopez, "Liquid chromatography-tandem mass spectrometry for the determination of protein-bound residues in shrimp dosed with nitrofurans," Journal of Agricultural and Food Chemistry, vol. 53, no. 23, pp. 8934-8939, 2005.

[9] X. Zhang, D. Zhang, and K. He, "Combining an effective immuno-affinity column with ELISA for reliable and visual detection of furaltadone metabolites in aquatic products," Analytical Methods, vol. 11, no. 9, pp. 1270-1275, 2019.

[10] S. Bogialli and A. Di Corcia, "Recent applications of liquid chromatography-mass spectrometry to residue analysis of antimicrobials in food of animal origin," Analytical and Bioanalytical Chemistry, vol. 395, no. 4, pp. 947-966, 2009.

[11] W. Wu, S. Yang, J. Liu et al., "Progress in immunoassays for nitrofurans detection," Food and Agricultural Immunology, vol. 31, no. 1, pp. 907-926, 2020.

[12] K. Wang, Y. Kou, M. Wang, X. Ma, and J. Wang, "Determination of Nitrofuran metabolites in fish by ultraperformance liquid chromatography-photodiode array detection with thermostatic ultrasound-assisted derivatization," ACS Omega, vol. 5, no. 30, pp. 18887-18893, 2020.

[13] R. Kyuchukova, "Antibiotic residues and human health hazard-review," Bulgarian Journal of Agricultural Science, vol. 26, pp. 664-668, 2020.

[14] C. Douny, J. Widart, E. De Pauw et al., "Development of an analytical method to detect metabolites of nitrofurans," Aquaculture, vol. 376-379, pp. 54-58, 2013.

[15] Z. Li, Z. Li, and D. Xu, "Simultaneous detection of four nitrofuran metabolites in honey by using a visualized microarray screen assay," Food Chemistry, vol. 221, pp. 1813-1821, 2017.

[16] R. J. McCracken and D. Glenn Kennedy, "Determination of furazolidone in animal feeds using liquid chromatography with UV and thermospray mass spectrometric detection," Journal of Chromatography A, vol. 771, no. 1, pp. 349-354, 1997.

[17] European Commission, Commission Regulation (EC) No 1442/95 of 26 June 1995 Amending Annexes I, II, III and IV of Council Regulation (EEC) No 2377/90 Laying down a Community Procedure for the Establishment of Maximum Residue Limits of Veterinary Medicinal Products in Foodstuffs of Animal Origin, pp. 26-30, 1995.
[18] European Union, 2003/181/EC: Commission Decision of 13 March 2003 Amending Decision 2002/657/EC as Regards the Setting of Minimum Required Performance Limits (MRPLs) for Certain Residues in Food of Animal Origin (Text with EEA Relevance) (notified under document number C (2003) 764), European Union, Brussels, Belgium, 2003.

[19] EFSA Panel on Contaminants in the Food Chain (CONTAM), "Scientific Opinion on nitrofurans and their metabolites in food," EFSA Journal, vol. 13, no. 6, p. 4140, 2015.

[20] Commission Regulation (EU), 2019/1871 of 7 November 2019 on reference points for action for non-allowed pharmacologically active substances present in food of animal origin and repealing decision 2005/34/EC (text with EEA relevance), European Union, Brussels, Belgium, 2019.

[21] T. P. Van Boeckel, C. Brower, M. Gilbert et al., "Global trends in antimicrobial use in food animals," Proceedings of the National Academy of Sciences of the United States of America, vol. 112, no. 18, pp. 5649-5654, 2015.

[22] L. Rodziewicz, "Determination of nitrofuran metabolites in milk by liquid chromatography-electrospray ionization tandem mass spectrometry," Journal of Chromatography, B Analytical Technologies in the Biomedical and Life Sciences, vol. 864, no. 1-2, pp. 156-160, 2008.

[23] J. Barbosa, S. Moura, R. Barbosa, F. Ramos, and M. I. Da Silveira, "Determination of nitrofurans in animal feeds by liquid chromatography-UV photodiode array detection and liquid chromatography-ionspray tandem mass spectrometry," Analytica Chimica Acta, vol. 586, no. 1-2, pp. 359-365, 2007.

[24] N.-N. Du, M.-M. Chen, L.-Q. Sheng et al., "Determination of nitrofuran metabolites in shrimp by high performance liquid chromatography with fluorescence detection and liquid chromatography-tandem mass spectrometry using a new derivatization reagent," Journal of Chromatography A, vol. 1327, pp. 90-96, 2014.

[25] W. Jiang, P. Luo, X. Wang et al., "Development of an enzymelinked immunosorbent assay for the detection of nitrofurantoin metabolite, 1-amino-hydantoin, in animal tissues," Food Control, vol. 23, no. 1, pp. 20-25, 2012.

[26] M. S. Park, K. T. Kim, and J. S. Kang, "Development of an analytical method for detecting nitrofurans in bee pollen by liquid chromatography-electrospray ionization tandem mass spectrometry," Journal of Chromatography, B Analytical Technologies in the Biomedical and Life Sciences, vol. 1046, pp. 172-176, 2017.

[27] P. Thongsrisomboon, B. Liawruangrath, S. Liawruangrath, and S. Satienperakul, "Determination of nitrofurans residues in animal feeds by flow injection chemiluminescence procedure," Food Chemistry, vol. 123, no. 3, pp. 834-839, 2010.

[28] A. Radovnikovic, M. Moloney, P. Byrne, and M. Danaher, "Detection of banned nitrofuran metabolites in animal plasma samples using UHPLC-MS/MS," Journal of Chromatography, $B$ Analytical Technologies in the Biomedical and Life Sciences, vol. 879, no. 2, pp. 159-166, 2011.

[29] T. Wei, G. Li, and Z. Zhang, "Rapid determination of trace semicarbazide in flour products by high-performance liquid chromatography based on a nucleophilic substitution reaction," Journal of Separation Science, vol. 40, no. 9, pp. 1993-2001, 2017.

[30] L. Tribalat, O. Paisse, G. Dessalces, and M. F. GrenierLoustalot, "Advantages of LC-MS-MS compared to LC-MS for the determination of nitrofuran residues in honey," $A n$ alytical and Bioanalytical Chemistry, vol. 386, no. 7-8, pp. 2161-2168, 2006. 
[31] M. I. Lopez, M. F. Feldlaufer, A. D. Williams, and P.-S. Chu, "Determination and confirmation of nitrofuran residues in honey using LC-MS/MS," Journal of Agricultural and Food Chemistry, vol. 55, no. 4, pp. 1103-1108, 2007.

[32] B. T. Veach, R. Anglin, T. K. Mudalige, and P. J. Barnes, "Quantitation and confirmation of Chloramphenicol, Florfenicol, and Nitrofuran Metabolites in honey using LC-MS/ MS," Journal of AOAC International, vol. 101, no. 3, pp. 897-904, 2018.

[33] S.-P. Khong, E. Gremaud, J. Richoz et al., "Analysis of matrixbound nitrofuran residues in worldwide-originated honeys by isotope dilution high-performance liquid chromatography-tandem mass spectrometry," Journal of Agricultural and Food Chemistry, vol. 52, no. 17, pp. 5309-5315, 2004.

[34] A. Kaufmann, P. Butcher, K. Maden, S. Walker, and M. Widmer, "Determination of nitrofuran and chloramphenicol residues by high resolution mass spectrometry versus tandem quadrupole mass spectrometry," Analytica Chimica Acta, vol. 862, pp. 41-52, 2015.

[35] F. Alkan, A. Kotan, and N. Ozdemir, "Development and validation of confirmatory method for analysis of nitrofuran metabolites in milk, honey, poultry meat and fish by liquid chromatography-mass spectrometry," Macedonian Veterinary Review, vol. 39, no. 1, pp. 15-22, 2016.

[36] L. Rodziewicz, "Determination of nitrofuran metabolites in milk by liquid chromatography-electrospray ionization tandem mass spectrometry," Journal of Chromatography. B, Analytical Technologies in the Biomedical and Life Sciences, vol. 864, no. 1-2, pp. 156-160, 2008.

[37] P.-S. Chu and M. I. Lopez, "Determination of nitrofuran residues in milk of dairy cows using liquid chromatography-tandem mass spectrometry," Journal of Agricultural and Food Chemistry, vol. 55, no. 6, pp. 2129-2135, 2007.

[38] R. A. Pearson, C. Evans, and J. G. Bendall, "Nitrofurazone quantification in milk at the European Union minimum required performance limit of $1 \mathrm{ng} g(-1)$ : circumventing the semicarbazide problem," Food Additives \& Contaminants. Part A, Chemistry, Analysis, Control, Exposure \& Risk Assessment, vol. 33, no. 8, pp. 1324-1336, 2016.

[39] Z. Zhang, Y. Wu, X. Li et al., "Multi-class method for the determination of nitroimidazoles, nitrofurans, and chloramphenicol in chicken muscle and egg by dispersive-solid phase extraction and ultra-high performance liquid chromatography-tandem mass spectrometry," Food Chemistry, vol. 217, pp. 182-190, 2017.

[40] A. Conneely, A. Nugent, M. O'Keeffe et al., "Isolation of bound residues of nitrofuran drugs from tissue by solid-phase extraction with determination by liquid chromatography with UV and tandem mass spectrometric detection," Analytica Chimica Acta, vol. 483, no. 1, pp. 91-98, 2003.

[41] E. Verdon, P. Couedor, and P. Sanders, "Multi-residue monitoring for the simultaneous determination of five nitrofurans (furazolidone, furaltadone, nitrofurazone, nitrofurantoine, nifursol) in poultry muscle tissue through the detection of their five major metabolites (AOZ, AMOZ, SEM, AHD, DNSAH) by liquid chromatography coupled to electrospray tandem mass spectrometry--in-house validation in line with commission decision 657/2002/EC," Analytica Chimica Acta, vol. 586, no. 1-2, pp. 336-347, 2007.

[42] X. Xia, X. Li, S. Zhang et al., "Simultaneous determination of 5-nitroimidazoles and nitrofurans in pork by high-performance liquid chromatography-tandem mass spectrometry," Journal of Chromatography A, vol. 1208, no. 1, pp. 101-108, 2008.
[43] A. V. Kulikovskii, I. F. Gorlov, M. I. Slozhenkina, N. L. Vostrikova, A. N. Ivankin, and O. A. Kuznetsova, "Determination of nitrofuran metabolites in muscular tissue by high-performance liquid chromatography with mass spectrometric detection," Journal of Analytical Chemistry, vol. 74, no. 9, pp. 906-912, 2019.

[44] N. M. Valera-Tarifa, P. Plaza-Bolaños, R. Romero-González, J. L. Martínez-Vidal, and A. Garrido-Frenich, "Determination of nitrofuran metabolites in seafood by ultrahigh performance liquid chromatography coupled to triple quadrupole tandem mass spectrometry," Journal of Food Composition and Analysis, vol. 30, no. 2, pp. 86-93, 2013.

[45] Y. Zhang, H. Qiao, C. Chen, Z. Wang, and X. Xia, "Determination of nitrofurans metabolites residues in aquatic products by ultra-performance liquid chromatography-tandem mass spectrometry," Food Chemistry, vol. 192, pp. 612617, 2016.

[46] S. Szilagyi and B. De La Calle, "Development and validation of an analytical method for the determination of semicarbazide in fresh egg and in egg powder based on the use of liquid chromatography tandem mass spectrometry," Analytica Chimica Acta, vol. 572, no. 1, pp. 113-120, 2006.

[47] Z. Zhang, Y. Wu, X. Li et al., "Multi-class method for the determination of nitroimidazoles, nitrofurans, and chloramphenicol in chicken muscle and egg by dispersive-solid phase extraction and ultra-high performance liquid chromatography-tandem mass spectrometry," Food Chemistry, vol. 217, pp. 182-190, 2017.

[48] C. L. Arthur and J. Pawliszyn, "Solid phase microextraction with thermal desorption using fused silica optical fibers," Analytical Chemistry, vol. 62, no. 19, pp. 2145-2148, 1990.

[49] H. Lord and J. Pawliszyn, "Evolution of solid-phase microextraction technology," Journal of Chromatography A, vol. 885, no. 1-2, pp. 153-193, 2000.

[50] V. Jalili, A. Barkhordari, and A. Ghiasvand, "A comprehensive look at solid-phase microextraction technique: a review of reviews," Microchemical Journal, vol. 152, Article ID 104319, 2020.

[51] M. Lashgari, V. Singh, and J. Pawliszyn, "A critical review on regulatory sample preparation methods: validating solidphase microextraction techniques," TRAC Trends in Analytical Chemistry, vol. 119, Article ID 115618, 2019.

[52] W. Filipiak and B. Bojko, "SPME in clinical, pharmaceutical, and biotechnological research - how far are we from daily practice?" TRAC Trends in Analytical Chemistry, vol. 115, pp. 203-213, 2019.

[53] S. Huang, G. Chen, N. Ye et al., "Solid-phase microextraction: an appealing alternative for the determination of endogenous substances - a review," Analytica Chimica Acta, vol. 1077, pp. 67-86, 2019.

[54] H. Piri-Moghadam, M. N. Alam, and J. Pawliszyn, "Review of geometries and coating materials in solid phase microextraction: opportunities, limitations, and future perspectives," Analytica Chimica Acta, vol. 984, pp. 42-65, 2017.

[55] J. Deng, Y. Yang, L. Fang, L. Lin, H. Zhou, and T. Luan, "Coupling solid-phase microextraction with ambient mass spectrometry using surface coated wooden-tip probe for rapid analysis of ultra trace perfluorinated compounds in complex samples," Analytical Chemistry, vol. 86, no. 22, pp. 11159-11166, 2014.

[56] Y. Liu, Q. Yang, X. Chen et al., "Sensitive analysis of trace macrolide antibiotics in complex food samples by ambient mass spectrometry with molecularly imprinted polymercoated wooden tips," Talanta, vol. 204, pp. 238-247, 2019. 
[57] Y. Huang, Y. Ma, H. Hu et al., "Rapid and sensitive detection of trace malachite green and its metabolite in aquatic products using molecularly imprinted polymer-coated wooden-tip electrospray ionization mass spectrometry," RSC Advances, vol. 7, no. 82, pp. 52091-52100, 2017.

[58] B. Hu, P.-K. So, H. Chen, and Z.-P. Yao, "Electrospray ionization using wooden tips," Analytical Chemistry, vol. 83, no. 21, pp. 8201-8207, 2011.

[59] China National Standardization Administration Committee, GB/T. 27404-2008.Criterion on Quality Control of Laboratories-Chemical Testing of Food., China National Standardization Administration Committee, Beijing, China, 2008.

[60] H. K. Sasmaz, T. Uzlasir, and H. Kelebek, "Effect of infusion time on the phenolic profile and some physicochemical properties of Lavandula $\mathrm{x}$ intermedia cv. "SUPER", Journal of Raw Materials to Processed Foods, vol. 1, pp. 55-71, 2020.

[61] L. Hartig and K. V. Czapiewski, "Detecting nitrofuran metabolites in animal products using LC/MS/MS," Spectroscopy Europe, vol. 17, no. 3, pp. 21-23, 2005.

[62] P. Mottier, S.-P. Khong, E. Gremaud et al., "Quantitative determination of four nitrofuran metabolites in meat by isotope dilution liquid chromatography-electrospray ionisation-tandem mass spectrometry," Journal of Chromatography $A$, vol. 1067, no. 1, pp. 85-91, 2005.

[63] Standardization Administration of China, GB/T. 20752-2006, Method for the Determination Residues of the Metabolites of Nitrofuran in Pork, Beef Chicken, Porcine Liver and Aquatic products-LC-MS-MS Method, Standardization Administration of China, Beijing, China, 2006. 